\title{
The Relationship between Strength-Based Parenting with Children's Stress Levels and Strength-Based Coping Approaches
}

\author{
Lea Waters \\ Melbourne Graduate School of Education, University of Melbourne, Melbourne, Australia \\ Email: waters@unimelb.edu.au
}

Received 26 March 2015; accepted 5 May 2015; published 6 May 2015

Copyright (C) 2015 by author and Scientific Research Publishing Inc.

This work is licensed under the Creative Commons Attribution International License (CC BY). http://creativecommons.org/licenses/by/4.0/

(c) (i) Open Access

\section{Abstract}

The current study adopted a positive psychology approach to examine the role of a positively oriented style of parenting - strength-based parenting (SBP)—on levels of stress in primary school aged children. Specifically, the study tested the degree to which SBP was directly and indirectly related to stress levels in children, partly through its influence on children' coping responses. A community sample of Australian upper-primary school aged children $\left(N=103 ; M_{\text {age }}=11.30 ; S D=\right.$ 1.10; $57 \%$ female, $43 \%$ male) participated in a cross-sectional, mixed methods field study using self-report surveys and behavioral vignette. A series of multiple regression analyses found that SBP was significantly negatively related to stress levels and significantly positively related to strength-based coping in children. In addition, strength-based coping partially mediated the relationship between SBP and stress levels in children, suggesting that one reason why SBP reduced stress in children was that it encouraged children to take strength-based coping approaches when faced with adversity. SBP thus increases the endogenous resources (i.e., personal strengths) that children can draw upon to address resources with demands that leads to stress. The discussion provides practical implications for SBP and suggestions for future research in this area.

\section{Keywords}

Parenting, Positive Psychology, Strengths, Coping, Stress

\section{Introduction}

Stress can be defined as a set of physiological, psychological and behavioural reactions to stimuli (good or bad) that threaten a person's well-being (Palmer, 1989). Stress is typically brought about by an imbalance in demands 
and resources (Lazarus \& Folkman, 1984), arising when a person perceives that he cannot adequately cope with the demands being placed upon him (Lazarus, 1966). In this way, stress is a phenomenon that is caused by a mismatch between demands and resources, rather than the demands of the environment itself (Cox, 1978).

This understanding of stress is very important when considering the mental health of children, given that they are still going through key developmental milestones and have not yet fully developed the physical, psychological and social resources that enable them to cope with the demands that are placed upon them. Indeed, children regularly find themselves in situations where the demands and pressures of their environment exceed their resources and ability to cope, thus causing stress.

It is not surprising, then, that rates of childhood stress appear to be high. In the 2010 "Stress in America Survey" (APA, 2010), 20\% of children reported that they worried a lot or a great deal about things in their lives (8, 9 or 10 on a scale of 1 to 10 ). Sbaraini \& Schermann's (2008) results showed a comparable $18.2 \%$ stress prevalence in the fourth grade primary school children in Brazil. Similarly, in a large-scale Australian study of school students $(N>10,000), 31 \%$ of students reported feeling "very stressed", $40 \%$ said they worried too much and $40 \%$ reported that they had difficulties in staying calm (Bernard, Stephanau, \& Urbach, 2007). Despite these high levels of stress, the 2013 iteration of the "Stress in America Survey" (APA, 2014) revealed that 50\% of teenagers did not feel confident about their ability to handle their personal problems and $42 \%$ felt that they were not doing enough to manage their stress. These results point to high levels of stress in children and yet a lack of effective coping responses in children. How can we help children cope more effectively and positively with stress?

According to the United States Department of Health and Human Services Centers for Disease Control and Prevention (Middlebrooks \& Audage, 2008), children can experience three different types of stress: 1) toxic stress, 2) tolerable stress, and 3) positive stress. All three types of stress are triggered by adverse circumstances, but differ in the severity of the adversity, the degree to which the adverse circumstances endure, and the support that a child receives.

Toxic stress is triggered by intense adverse experiences that are sustained over long periods of time and where the child is unable to effectively manage the adverse event (e.g., domestic violence). Tolerable stress can come from a one-off intense event (e.g., death of a loved one) where the child has support and resources to heal and grow from the event. Positive stress, or minor stress, is triggered by everyday adverse situations (e.g., a challenging homework assignment or friendship issues) where the adversity is not extreme and is only short-lived. This type of stress causes minor physiological and psychological reactions, such as increased heart rate, increased cortisol levels, and feelings of anxiety, that are overcome once the demands of the situation dissipate or as the child develops greater capacity/resources to cope with these demands.

While toxic stress has been shown to have negative effects on brain development, immune functioning, cognitive functioning and social functioning during childhood (Lupien, McEwen, Gunnar, \& Heim, 2009), Middleb rooks \& Audage (2008) argue that positive stress is a normal part of the developmental process that helps children to develop the essential life skills of coping with and adapting to new situations.

Researchers have therefore investigated how a child's resources can be developed to help them grow and learn from positive stress. Within this line of inquiry, the role that parents play in helping children deal with stress has been investigated in non-clinical samples (Hardy, 1993; Healy, Sanders, \& Iyer, 2014; McLeod, Wood, \& Weisz, 2007; Wolfradt, Hempel, \& Miles, 2003) as well as special needs, at risk and clinical samples (Burgess, Sly, Morawska Cooper, \& Devadason, 2008; Morawska, Stelzer, \& Burgess 2008; Morawska \& Sanders, 2008; Tellegen \& Sanders, 2014). Summarizing the literature on the link between parenting and childhood stress, Power (2004) concluded that "Children who approach potentially stressful events with active forms of coping have parents who are warm and supportive, and who employ authoritative control practices" (Power, 2004: p. 305).

Middlebrooks \& Audage (2008) posit that the support of caring parents (and other adults) helps children to learn through positive stress and is also a critical factor in determining whether a child who experiences tolerable stress (e.g., death of a loved one) moves into toxic stress and psychological ill health or moves towards adversarial growth and psychological health following the stress.

The current study examines the role of parents in helping children to overcome and reduce their stress. The study focuses on positive, everyday stress and adopts a positive psychology approach to the research inquiry. In particular, the study examines the role of strength-based parenting (SBP) on stress levels in children. I define strength-based parenting as a style of parenting that seeks to deliberately identify and cultivate positive states, positive processes and positive qualities in one's children. 
According to Sheldon \& King (2001), positive psychology is principally about the scientific study of human strengths. Indeed, in a recent review of the field, Rusk \& Waters (2013) identified strengths as a major research topic in positive psychology. Strength enhancement, asset development and competency-based approaches are gaining momentum in other fields too (e.g., youth studies, education and family psychology), as effective ways to build well-being (Brown Kirshman et al., 2010; Sheridan \& Burt, 2009; White \& Waters, 2015).

Govindji \& Linley (2007) define strengths as "natural capacities that we yearn to use, that enable authentic expression, and that energise us" (Govindji \& Linley, 2007: p. 144). Govindji \& Linley (2007) found that subjective well-being was significantly predicted by the degree to which a person knows and uses their strengths. School-based strengths interventions, with students ranging from primary through to secondary school in the United States, the United Kingdom and Australia, have found that helping school students to identify their strengths increases hope, life satisfaction, school engagement, self-esteem and positive affect as well as reducing negative affect (Linley \& Harrington, 2006; Madden, Green, \& Grant, 2010; Proctor, Tsukayama, Wood, Maltby, Eades, \& Linley, 2011; Seligman, Ernst, Gillham, Reivich, \& Linkins, 2009; Waters, 2011).

In the above school-based interventions, teachers taught children about their strengths. To date, however, there has been no research conducted on the effect that parents who adopt a strength-based approach may have upon the well-being, coping approaches and stress levels of their children.

\subsection{Could Strength-Based Parenting Help Children Cope with Stress?}

A major role of parenting is to create a safe attachment (Bowlby, 1969/1982). Safe attachment allows the child to engage in exploratory behavior, slowly becoming more autonomous and independent as they discover that they can cope with the demands of life.

What does SBP add to safe attachment? I contend that SBP motivates children to explore new situations, including stressful situations, through their strengths and this means that they interact with their environments using their positive traits and engaging in positive, adaptive processes. In this way, SBP adds a "positive filter" to the way a child reacts to stress, meaning that they are likely to reap the benefits of positive stress, such as skill development and adaptability.

When parents adopt a strength-based approach, they seek to deliberately identify and cultivate positive states, positive processes and positive qualities in their children. In other words, parents are building up their children's resources. Given that stress results from an imbalance between demands and resources, SBP is likely to help children to deal with stress because it builds up the child's resources (i.e., their strengths), thus fostering a better balance between the demands placed on the child and the strengths the child has to meet those demands.

By creating a positive filter and by building up resources, SBP should directly reduce the amount of stress a child feels in the first place. However, should a child go on to experience stress, SBP could also have an indirect effect by promoting strength-based coping in children that helps them to overcome or reduce stress once it is experienced.

Coping is defined as the thoughts and actions one uses to manage demands in life (Lazarus \& Folkman, 1984). Strength-based coping is a particular style of coping where the individual makes the best use of their personal strengths, their skills, their emotions, and their family and social resources to deal with stress (Drolet, Paquin, \& Soutyrine, 2007; Myers, 2003). SBP connects children with their strengths so that they will naturally use their own strengths to cope effectively with a stressful situation, rather than engaging in avoidance or aggressive coping responses. Let's take the common example of friendship conflict experienced by most children. SBP can assist children to approach a problem like this through strength-based coping skills such as social intelligence, fairness, perspective, emotional regulation and kindness, to effectively manage the conflict.

\subsection{Testing a Mediated Model}

The current study will test a partially mediated model for the direct and indirect effects of SBP on a child's levels of stress. The idea in mediation analysis is that some of the effect of the independent variable is transmitted to the dependent variable through a mediator variable. In addition, some of the effect of the independent variable passes directly to the dependent variable. That portion of the effect of the independent variable that passes through the mediator variable is the indirect effect (Aiken \& West, 1991; MacKinnon, 2008). In this study, it is predicted that SBP has a direct, negative relationship with stress and also has an indirect effect on stress through its positive relationship on children adopting strength-based coping.

MacKinnon \& Luecken (2008) recommend that mediation can be present when there is a significant relation 
between an independent variable (e.g., SBP) and the mediating variable (e.g., strength-based coping), and when there is also a significant relationship between the mediating variable (e.g. strength-based coping) and the dependent variable (e.g., stress) when accounting for the independent variable. Moreover, mediation requires that the independent variable precedes the mediator (e.g., SBP leads children to adopt strength-based coping) and the mediator must precede the dependent variable (e.g. strength-based coping inversely predicts stress). This relationship is represented in Figure 1.

The current study tests the following four hypotheses:

Hypothesis 1: Children's reports of the degree to which their parents use SBP will be inversely related to their own levels of general stress.

Hypothesis 2: The degree to which children use strength-based coping when confronted with minor stress will be inversely related to their levels of general stress.

Hypothesis 3: When confronted with minor stress, the degree to which children use strength-based coping will be positively related to the degree to which they report receiving SBP.

Hypothesis 4: The relationship between strength-based coping and stress will be partially mediated by the children's reports of the degree to which their parents use SBP.

\section{Method}

\subsection{Participants}

A community sample of Australian upper primary school-aged children participated in this study $(N=103$; Age range $=10-12$ years; $M_{\text {age }}=11.30 ; S D=1.1 ; 57 \%$ female, $43 \%$ male). Participants were recruited through a stress-management workshop that was run for children and facilitated by the researcher (a registered psychologist $)^{1}$. The most common family structure was a two parent household $(67 \%)$, with $29 \%$ coming from single parent household and $4 \%$ other (e.g. living with grandparents or other care giver). In terms of socioeconomic status, $52 \%$ of children came from families with household incomes above the Australian average. The two major ethnicity groups were children of European (53\%) and Asian descent (42\%), with 5\% in the 'other' category.

\subsection{Procedure}

This study used a cross-sectional field design with self-report surveys and a vignette behavioral test. At the start of the workshop, children completed a brief survey that assessed levels of stress and the degree to which they felt that their parents used a strength-based approach to parenting. The facilitator then hosted a discussion with the children about their survey responses with regard to stress and how it makes them feel. Next, the students were given two vignettes that portrayed common examples of minor, positive stress (i.e., stress that is low in adversity and is a one-off situation). After reading these two vignettes the children wrote about how they could deal with the situation. Following this, the children talked about their answers as a group with the workshop facilitator and completed a series of stress management activities over the remainder of the two-hour workshop.

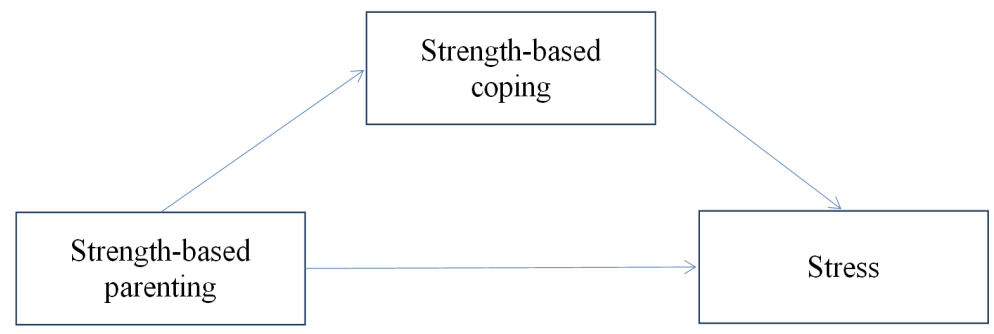

Figure 1. Mediation model for strength-based parenting as a mediator of the relationship between strength-based coping and stress in children.

\footnotetext{
${ }^{1}$ The workshop was limited to 30 participants and was repeated four times with a total of 119 children. When parents enrolled their children for the workshop they were asked to give consent to the release of the surveys that their children completed in the workshop. 103 parents agreed to release the surveys to be used for research purposes. No statistical differences were found between responses from children whose surveys were released and not released.
} 


\subsection{Materials}

\subsubsection{Vignettes}

Research vignettes are characterized by Hill (1997) as short scenarios that elicit responses to typical situations. Hazel (1995) suggests that vignettes are a valid way of gaining access to the thoughts and behaviors of participants in specific contexts. Vignettes give the researcher an "insider" position on participants' thoughts and selfbeliefs and have been used successfully with children in past research (Barter \& Renold, 2000; MacAuley, 1996; Miller-Perrin, Wurtele, \& Kondrick, 1990).

In the current study, two vignettes were developed based on guidelines given by Clarke \& Braun (2013). One vignette represented relationship stress and the other represented task stress. Both were designed to be at the level of positive, minor stress (rather than tolerable or toxic stress). The vignettes are outlined below.

Vignette 1 "You and your friend have been playing together in the school yard at lunch time all week. Your favorite game has been on the playground equipment. Today your friend got upset at you and said that you had more turns that him ${ }^{2}$ and that he needs to have many more turns than you tomorrow. But you feel that he has had more turns than you and it should be you who gets more turns tomorrow. Your friend said he is not going to play with you tomorrow unless you give him more turns. How will you approach this situation when you see your friend tomorrow at school? Write down your ideas on the page below".

Vignette 2 "Today is Tuesday and you have a major homework project due on Friday. Even though the teacher gave you this project last week you have not yet started it. Your teacher asked the students in your class to raise their hands if they had already started their assignment and you are the only one who has not started. How will you approach this situation when you get home tonight? Write down your ideas on the page below."

\subsubsection{Measures}

Strength-based parenting A modified version of Govindji \& Linley's (2007) Strengths Use Scale (SUS) was used. The SUS scale consists of 14 items such as "I am regularly able to do what I do best" and "I use my strengths everyday". Items were scored on a 5-point Likert scale $(1=$ strongly disagree; $5=$ strongly agree $)$. Govindji \& Linley report a Cronbach alpha reliability of 0.95 . Cronbach alpha reliability in the current sample was 0.94 . The wording of the SUS was modified to measure children's perceptions of parenting behaviors for both of their parents. For example, the item "I am aware of my strengths" was adjusted to "My parents are aware of my strengths" and the item "I am able to use my strengths in lots of different situations" was altered to "My parents encourage me to use my strengths in lots of different situations".

Stress The stress subscale of the Depression, Stress and Anxiety survey (DASS) was used (Lovibond \& Lovibond, 1995). The stress subscale consists of 14 items such as "I find it hard to calm down after something upsets me" and "I use a lot of nervous energy". The children were asked to rate how well each statement described them on a 5 -point Likert scale $(1=$ strongly disagree; $5=$ strongly agree $)$. This scale has been used in other child and adolescent samples and has shown acceptable psychometric properties (Duffy, Cunningham, \& Moore, 2005; Szabó \& Lovibond, 2006; Szabó, 2010). In an Australian sample, Patrick, Dyck, \& Bramston (2010) report Cronbach alpha reliability ranging from $0.94-0.96$ in children of the same age as the current study. Cronbach alpha reliability in the current sample was 0.87 .

Strength-based coping The two vignettes tested the behavioral reactions that students reported they would engage in when facing two cases of minor stress. Two researchers coded each child's response to rate the degree to which the coping efforts were strength-based. Specifically, the written responses of each child was coded for evidence that the child coped by a) creating positive states, and/or b) using positive processes and/or c) employing their positive qualities. For each specific example of strength-based coping in the written response, a score of 1 was given. An overall strength-based coping score was then created for each child.

Examples of children creating positive states included children reporting that they would do some deep breathing to calm themselves down (a response given to the homework stress vignette) and they would remind themselves of happy times they had with the friend (a response given to the friendship stress vignette). Examples of children using creating positive processes included children suggesting that they would talk to their friends, teachers or parents to find a fair solution (a response given to the friendship stress vignette) and they would write up an action plan (a response given to the homework stress vignette). Examples of children drawing on their own positive qualities included students reporting that they could use their internet skills to start re-

\footnotetext{
${ }^{2}$ This wording was changed to "her" for female students.
} 
searching for their assignment (a response given to the homework stress vignette) and that they would use their kindness to let their friend have more turns (a response given to the friendship stress vignette).

\section{Results}

\subsection{Descriptive and Correlation Analyses}

Table 1 shows the descriptive and correlation analyses performed for this study. Both the mean and mode scores for stress in this sample of children were at the mid-point of the scale, with the median being slightly below the mid-point, suggesting that this youth sample had middling levels of stress. The mean, mode and median scores for SBP in this sample of children were below the mid-point of the scale maximum, suggesting that children were rating their parents' use of SBP as lower than the middle point. Stress ratings by the children were significantly, negatively related to their ratings of the degree to which they receive SBP and the degree to which they would use strength-based coping in the 2 minor stress vignettes. Ratings of SBP were positively related to children's use of strength-based coping.

\begin{tabular}{|c|c|c|c|c|c|c|}
\hline & $\begin{array}{l}\text { Mean } \\
(S D)\end{array}$ & $\begin{array}{c}\text { Mode } \\
\text { (median) }\end{array}$ & $\begin{array}{l}\text { Max. score } \\
\text { (range) }\end{array}$ & 1. & 2. & 3. \\
\hline 1. Stress & $\begin{array}{c}35.33 \\
(11.39)\end{array}$ & $\begin{array}{c}35 \\
(33.5)\end{array}$ & $\begin{array}{c}70 \\
(16-65)\end{array}$ & - & & \\
\hline 2. Strength-based parenting & $\begin{array}{c}32.28 \\
(12.89)\end{array}$ & $\begin{array}{c}28 \\
(32.00)\end{array}$ & $\begin{array}{c}70 \\
(14-64)\end{array}$ & $-0.62^{* *}$ & - & \\
\hline 3. Strength-based coping & $\begin{array}{c}2.46 \\
(2.02)\end{array}$ & $\begin{array}{c}2.00 \\
(2.99)\end{array}$ & $\begin{array}{c}\text { N/A } \\
(0-7)\end{array}$ & $-0.52^{* *}$ & $.39^{* *}$ & - \\
\hline
\end{tabular}

\subsection{Mediation Analysis}

The four-step causal approach outlined by Baron \& Kenny (1986) and Kenny, Kashy, \& Bolger (1998) was used to test the mediation model. First, according to this model, there must be a significant relationship between the independent variable to the dependent variable. In the current study SBP was significantly, negatively related to stress, $\beta=-0.62, t(103)=-8.03, p<0.001$. SBP explained a significant proportion of variance in depression scores, $R^{2}=.39, F(1,103)=64.46, p<0.001$.

Second, there must be a significant relationship of the independent variable to the hypothesized mediating variable. This step was supported in the current analysis as SBP was significantly, positively related to strengthbased coping, $\beta=0.39, t(100)=4.27, p<0.001$, accounting for $15 \%$ of the variance in strength-based coping, $R^{2}=.15, F(1,100)=18.26, p<0.001$.

Third, the mediating variable must be significantly related to the dependent variable. In the current study, strength-based coping was significantly, negatively related to stress, $\beta=-0.52, t(100)=-6.512, p<0.001$. Strength-based coping predicted $26 \%$ of the variance in stress, $R^{2}=.26, F(1,100)=37.40, p<0.001$.

Fourth, when both the independent variable and mediating variable are entered as predictors of the dependent variable, the model requires that the coefficient relating the independent variable to the dependent variable must be smaller than it was in step one (Step $1 \beta=-0.62$; Step $4 \beta=-0.49$ ) and must be larger (in absolute value) than the coefficient relating the mediating variable to the dependent variable (SBP $\beta=-0.49$; strength-based coping $\beta=-0.33$ ). This step was supported in the current study. Moreover, the dependent variable retained significance, thus supporting hypothesis four, for a partial mediation. In combination, SBP and strength-based coping accounted for $47 \%$ of the variance in stress; $R^{2}=0.47, F(2,99)=42.05, p<0.001$. These results are reported in Figure 2.

\section{Discussion}

The current study examined the role of a positively oriented style of parenting - SBP — on levels of stress in primary school aged children. The study is the first to adapt Govindji \& Linley's (2007) strength use scale in order to examine the degree to which parents encourage their children to use strengths. It was predicted that SBP 


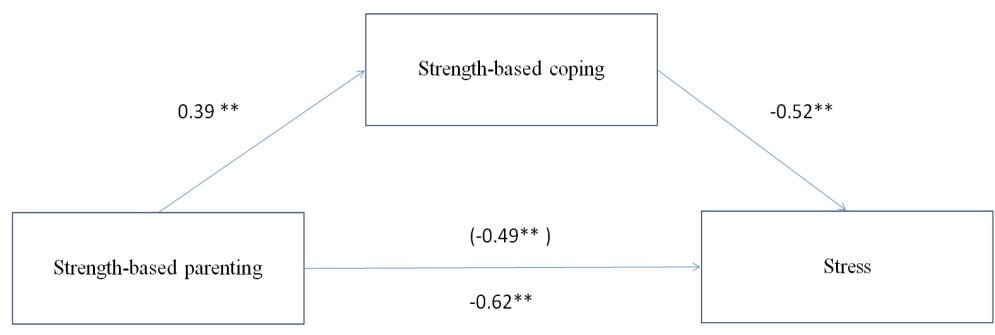

Figure 2. Path diagram of mediation model for strength-based parenting as a mediator of the relationship between strength-based coping and stress in children.

would have a direct, negative relationship with stress and would also have an indirect negative effect on stress through its positive relationship on children adopting strength-based coping. These predictions were supported by the current data.

The overall conclusion to be formed from this study is that parents may make a positive difference on their children's stress levels. These findings are consistent with past research and point to the important role that parents, and a particular style of parenting (i.e., SBP), plays in cultivating well-being and buffering ill-being in their sons and daughters. As stated by Bernard et al. (2007), "parenting is a crucial contributor to children's social and emotional well-being" (Bernard et al., 2007: p. 7). In Bernard \& colleagues' study, children with higher levels of social and emotional well-being reported that they had parents who were more likely to accept them for who they were, accommodate their interests, make time for them, and connect them to strengths/positive processes such as problem solving and organization skills together with character strengths such as persistence, respect, honesty, fairness and caring.

The current study tested two pathways to understand the effect of SBP on childhood stress. The first pathway hypothesized a direct, inverse effect of SBP on stress. This hypothesis was supported and those children who rated their parents higher on SBP also reported lower levels of stress. Successful adaptation to stress involves drawing upon one's resources in order to manage one's emotions, think clearly, and regulate one' behavior. These processes require self-knowledge and it has been suggested in this paper that SBP provides children with a positive filter from which to view themselves and learn about the strengths and resources they have available to them as they interact with the world.

The second pathway hypothesized an indirect effect of SBP on stress through its influence on strength-based coping. Hypotheses two, three and four were all supported in this study. Children who reported higher levels of SBP were also more likely to use strength-based coping approaches to the two minor stress vignettes. Additionally, the use of strength-based coping was significantly, negatively related to stress.

Strength-based coping is a particular style of coping where the individual makes the best use of their personal strengths, their skills, their emotions, and their family and social resources to deal with stress. SBP connects children with their strengths so that they are more likely to cope with adversity by drawing on their strengths rather than engaging in avoidance or aggressive coping responses. In this way, SBP can serve to increase the endogenous resources (i.e., personal strengths) that children draw upon to address the demands of their environment. The increases in a child's strength-based coping resources that come from SBP increases the balance between the demands of the environment and the resources that a child has to meet those demands, thus creating less stress for this child.

\subsection{Methodological Considerations and Future Research}

This study has a number of factors that might limit the generalizability of the results. First, the sample size was reasonably small which results in less precise estimates of the population means. A larger sample would be able to achieve closer approximations of the population means, as well as increasing the representativeness of the population (in this case upper primary school children).

Second, the study used a cross-sectional design with correlational data which precludes causal inferences. As such, we cannot say conclusively whether SBP influences children to adopt SBC and have lower stress. There may be an additional factor that is connecting these three variables (e.g., personality) or it may be that children who adopt SBC tend to interpret their parents behavior in strength based ways rather than SBP leading to child- 
ren adopting SBC. Although the direction put forward in this study (i.e., that SBP is the independent variable that predicts SBC and stress) is the most theoretically parsimonious, a stronger test of causality requires longitudinal and experimental data.

Third, the community sample of children was recruited from a stress management workshop. It may be that parents enrolled their children in this workshop because the children were high on stress which would mean that these results may not generalize to children with lower stress levels. However, the mean and standard deviation scores on the DASS were similar to another community sample of young people collected in another Australian sample (Patrick et al., 2010), and were at the mid-point on the DASS survey, which suggests that this is not a strong methodological flaw.

Fourth, this study measured SBP using children's reports rather than parents' reports. It may be that children either under-represented or over-estimated the degree of SBP they were actually receiving. Future research could use multi-source data and ask parents to rate their own level of SBP whilst collecting the dependent variable data from their children.

Having said this, parents and children may disagree about the degree to which a parent is using a strengthbased approach and it may be that the outcome variables for children are more closely linked with the child's perception of their parents' strengths approach rather than the parents actual approach. Further research could therefore investigate whether children's perceptions or parents' reports of SBP are stronger predictors of stress and strength-based coping.

The study also focused on positive, minor stress and it may be that the relationship between SBP, strengthbased coping and stress would be different if the stress was at tolerable or toxic levels. It could be that SBP plays an even stronger role when the stress becomes more intense or it may be that the effect of the parent diminishes against the face of extreme stress. Future research can investigate the relationship between SBP, strength-based coping and stress in children who experience tolerable or toxic levels of stress.

Although the focus on positive, minor stress in this study may limit its generalizability to children who experience more extreme stress, the focus on positive, minor stress can also be considered a strength of the current study given that this type of stress is the most common stress experienced by children, which means these results are more relevant to the stress that most children commonly experience.

Another strength of this study was the use of multiple methods of data collection, thus reducing the likelihood of common method bias. In particular, the behavioral vignettes gave a deeper context and understanding of the types of strength-based coping skills that young children adopt when confronted with minor stress.

\subsection{Practical Implications}

The current results suggest that parents may play a role in assisting their children to cope with everyday, minor stress by parenting in ways that assist children to understand their own strengths and engage in strength-based coping. However, the current study also showed that children were rating their parents below the mid-point on the SBP scale suggesting that this is a style of parenting which could be increased and is worthy of additional research.

While many parents are likely to understand the importance of providing love and emotional support (Eshel, Daelmans, de Mello, \& Martines, 2006), they may not be as aware of the importance of deliberately and systematically identifying and building strengths in their children.

There are two major ways in which parents can become more aware of their children's strengths. The first way is through strength surveys. The Strengths Explorer (Gallup Youth Development Specialists, 2007) and the Values in Action Youth Survey (http://www.viacharacter.org) can be completed from ages 10 - 11 onwards and have been developed by teams of psychologists to ensure that the surveys are valid and reliable. The surveys help parents and children to understand their unique strengths profile.

The second way for parents to become aware of their children's strengths is through the practice of strength spotting. Strength spotting is a process of observation that specifically looks to identify strengths in oneself and others (Linley, Garcea, Hill, Minhas, Trenier, \& Willars, 2010). Adapting Linley's (2008) guidelines on strength spotting to parenting, parents can look for 5 signals that point to a child's strengths. When children are using their strengths they: 1) are energized and display high levels of engagement during and after using the strength, 2) can become so engrossed they lose track of time, 3) show very rapid learning curves in areas that are strengths, 4) have a repeated pattern of successful performance in the area, and 5) are performing above age-appropriate le- 
vels in the skill or trait.

These two techniques (strengths surveys and strength spotting) can assist parents to adopt strength-based approaches with their children, thus increasing the child's own strength-based coping and reducing the child's stress.

The current study has been based at the individual level of analysis and had made suggestions for parents to use in a self-directed manner in order to increase their capacity to acknowledge and encourage their children's strengths use. The results of this research could also be fed into more formalized parenting program and can, thus, be woven into the research that looks at parenting from a public health perspective (Sanders, Bor, \& Morawska, 2007; Sanders \& Morawska, 2006).

\section{Conclusion}

Although toxic stress has debilitating effects on the well-being of children, not all stress is damaging. Positive stress has the potential to help children learn, grow and adapt if it is successfully managed. The current study shows that children are more likely to use their strengths to effectively cope with minor stress in their life if they have parents who adopt a strength-based approach to parenting. These contributions offer a new avenue for positive psychology research into parenting, which is, as yet, an under-explored but promising topic.

\section{References}

American Psychological Association (2010). Stress in America Findings. https://www.apa.org/news/press/releases/stress/2010/national-report.pdf

American Psychological Association (2014) Stress in America: Are Teens Adopting Adults' Stress Habits? http://www.apa.org/news/press/releases/stress/2013/stress-report.pdf

Baron, R. M., \& Kenny, D. A. (1986). The Moderator-Mediator Variable Distinction in Social Psychological Research: Conceptual, Strategic, and Statistical Considerations. Journal of Personality and Social Psychology, 51, 1173-1182.

http://dx.doi.org/10.1037/0022-3514.51.6.1173

Barter, C., \& Renold, E. (2000). "I Wanna Tell You a Story": Exploring the Application of Vignettes in Qualitative Research with Children and Young People. International Journal of Social Research Methodology, 3, 307-323. http://dx.doi.org/10.1080/13645570050178594

Bernard, M. E., Stephanau, A., \& Urbach, D. (2007). ASG Student Social and Emotional Health Report. Melbourne: Australian Council for Educational Research.

http://www.acer.edu.au/files/SEWB_ASG-StudentSocialEmotionalHealthReport.pdf

Bowlby, J. (1969/1982). Attachment and Loss. Attachment (2nd ed., Vol. 1). New York: Basic Books.

Brown Kirschman, K. J., Roberts, M. C., Shadlow, J. O., \& Pelley, T. J. (2010). An Evaluation of Hope Following a Summer Camp for Inner-City Youth. Child and Youth Care Forum, 39, 385-396. http://dx.doi.org/10.1007/s10566-010-9119-1

Bureau Aiken, L. S., \& West, S. G. (1991). Multiple Regression: Testing and Interpreting Interactions. Newbury Park, CA: Sage.

Burgess, S. W., Sly, P. D., Morawska, A., Cooper, D. M., \& Devadason, S. G. (2008). Assessing Adherence and Factors Associated with Adherence in Young Children with Asthma. Respirology, 13, 559-563. http://dx.doi.org/10.1111/j.1440-1843.2008.01292.x

Clarke, V., \& Braun, V. (2013). Successful Qualitative Research: A Practical Guide for Beginners. London: Sage.

Cox, T. (1978). Stress. Basingstoke: Macmillan Education.

Drolet, M., Paquin, M., \& Soutyrine, M. (2007). Strengths-Based Approach and Coping Strategies Used by Parents Whose Young Children Exhibit Violent Behaviour: Collaboration between Schools and Parents. Child and Adolescent Social Work Journal, 24, 437-453. http://dx.doi.org/10.1007/s10560-007-0094-9

Duffy, C. J., Cunningham, E. G., \& Moore, S. M. (2005). The Factor Structure of Mood States in an Early Adolescent Sample. Journal of Adolescence, 28, 677-680. http://dx.doi.org/10.1016/j.adolescence.2005.08.013

Eshel, N., Daelmans, B., de Mello, M. C., \& Martines, J. (2006). Responsive Parenting: Interventions and Outcomes. Bulletin of the World Health Organization, 84, 991-998. http://dx.doi.org/10.2471/BLT.06.030163

Gallup Youth Development Specialists (2007). Strengths Explorer for Ages 10 to 14: From Gallup, the Creators of Strengths Finder. Princeton, NJ: Gallup Press.

Govindji, R., \& Linley, P. A. (2007). Strengths Use, Self-Concordance and Well-Being: Implications for Strengths Coaching and Coaching Psychologists. International Coaching Psychology Review, 2, 143-153. 
Hardy, D. (1993). Examining the Relation of Parenting to Children's Coping with Everyday Stress. Child Development, 64, 1929-1941. http://dx.doi.org/10.2307/1131472

Hazel, N. (1995). Elicitation Techniques with Young People. Social Research Update, Issue 12. http://sru.soc.surrey.ac.uk/SRU12.html

Healy, K. L., Sanders, M. R., \& Iyer, A. (2014). Facilitative Parenting and Children's Social, Emotional and Behavioral Adjustment. Journal of Child and Family Studies.

Hill, M. (1997). Research Review: Participatory Research with Children. Child and Family Social Work, 2, 171-183.

Kenny, D. A., Kashy, D. A., \& Bolger, N. (1998). Data Analysis in Social Psychology. In D. T. Gilbert, S. T. Fiske, \& G. Lindzey (Eds.), The Handbook of Social Psychology (Vol. 1, pp. 233-265). New York: Oxford University Press.

Lazarus, R. S. (1966). Psychological Stress and the Coping Process. New York: McGraw-Hill.

Lazarus, R. S., \& Folkman, S. (1984). Stress, Appraisal and Coping. New York: Springer.

Linley, A. (2008). Average to A+: Realising Strengths in Yourself and Others. Coventry: CAPP Press.

Linley, P. A., \& Harrington, S. (2006). Playing to Your Strengths. The Psychologist, 19, 86-89.

Linley, P. A., Garcea, N., Hill, J., Minhas, G., Trenier, E., \& Willars, J. (2010). Strengthspotting in Coaching: Conceptualisation and Development of the Strengthspotting Scale. International Coaching Psychology Review, 5, 165-176.

Lovibond, S. H., \& Lovibond, P. F. (1995). Manual for the Depression Anxiety Stress Scales. Sydney: Psychology Foundation.

Lupien, S. J., McEwen, B. S., Gunnar, M. R., \& Heim, C. (2009). Effects of Stress throughout the Lifespan on the Brain, Behavior and Cognition. Nature Reviews Neuroscience, 10, 434-445. http://dx.doi.org/10.1038/nrn2639

MacAuley, C. (1996). Children in Long Term Foster Care: Emotional and Social Development. Hampshire: Avebury.

MacKinnon, D. P. (2008). Introduction to Statistical Mediation Analysis. Mahwah, NJ: Erlbaum.

MacKinnon, D. P., \& Luecken, L. J. (2008). How and for Whom? Mediation and Moderation in Health Psychology. Health Psychology, 27, S99-S100. http://dx.doi.org/10.1037/0278-6133.27.2(Suppl.).S99

Madden, W., Green, S., \& Grant, T. (2010). A Pilot Study Evaluating Strengths-Based Coaching for Primary School Students: Enhancing Engagement and Hope. International Coaching Psychology Review, 6, 71-83.

McLeod, B. D., Wood, J. J., \& Weisz, J. R. (2007). Examining the Association between Parenting and Childhood Anxiety: A Meta-Analysis. Clinical Psychology Review, 27, 155-172. http://dx.doi.org/10.1016/j.cpr.2006.09.002

Middlebrooks, J. S., \& Audage, N. C. (2008). The Effects of Childhood Stress on Health across the Lifespan. Atlanta, GA: Centers for Disease Control and Prevention, National Center for Injury Prevention and Control. http://stacks.cdc.gov/view/cdc/6978

Miller-Perrin, C. L., Wurtele, S. K., \& Kondrick, P. A. (1990). Sexually Abused and Non-Abused Children's Conceptions of Personal Body Safety. Child Abuse and Neglect, 14, 99-112. http://dx.doi.org/10.1016/0145-2134(90)90085-8

Morawska, A., \& Sanders, M. R. (2008). Parenting Gifted and Talented Children: What Are the Key Child Behavior and Parenting Issues? Australian and New Zealand Journal of Psychiatry, 42, 819-827. http://dx.doi.org/10.1080/00048670802277271

Morawska, A., Stelzer, J., \& Burgess, S. W. (2008). Parenting Asthmatic Children: Identification of Parenting Challenges. Journal of Asthma, 45, 465-472. http://dx.doi.org/10.1080/02770900802040050

Myers, J. E. (2003). Coping with Caregiving Stress: A Wellness-Oriented, Strengths-Based Approach for Family Counselors. The Family Journal, 11, 153-161. http://dx.doi.org/10.1177/1066480702250162

Palmer, S. (1989). Occupational Stress. The Health and Safety Practitioner, 7, 16-18.

Patrick, J., Dyck, M., \& Bramston, P. (2010). Depression Anxiety Stress Scale (DASS): Is It Valid for Adolescents? Journal of Clinical Psychology, 66, 996-1007.

Power, T. G. (2004). Stress and Coping in Childhood: The Parents' Role. Parenting: Science and Practice, 4, 271-317. http://dx.doi.org/10.1207/s15327922par0404 1

Proctor, C., Tsukayama, E., Wood, A. M., Maltby, J., Eades, J. F., \& Linley, P. A. (2011). Strengths Gym: The Impact of a Character Strengths-Based Intervention on the Life Satisfaction and Well-Being of Adolescents. Journal of Positive Psychology, 6, 377-388. http://dx.doi.org/10.1080/17439760.2011.594079

Rusk, R., \& Waters, L. (2013).Tracing the Size, Reach, Impact and Breadth of Positive Psychology. Journal of Positive Psychology, 8, 207-221. http://dx.doi.org/10.1080/17439760.2013.777766

Sanders, M. R., \& Morawska, A. (2006). Towards a Public Health Approach to Parenting. The Psychologist, 19, 476-479.

Sanders, M. R., Bor, W., \& Morawska, A. (2007). Maintenance of Treatment Gains: A Comparison of Enhanced, Standard, 
and Self-Directed Triple P-Positive Parenting Program. Journal of Abnormal Child Psychology, 35, 983-998. http://dx.doi.org/10.1007/s10802-007-9148-x

Sbaraini, C. R., \& Schermann, L. B. (2008). Prevalence of Childhood Stress and Associated Factors: A Study of Schoolchildren in a City in Rio Grande do Sul State, Brazil. Cad Saúde Pública, 24, 1082-1088. http://dx.doi.org/10.1590/S0102-311X2008000500015

Seligman, M. E., Ernst, R. M., Gillham, J., Reivich, K., \& Linkins, M. (2009). Positive Education: Positive Psychology and Classroom Interventions. Oxford Review of Education, 35, 293-311. http://dx.doi.org/10.1080/03054980902934563

Sheldon, K. M., \& King, L. K. (2001). Why Positive Psychology Is Necessary. American Psychologist, 56, $216-217$. http://dx.doi.org/10.1037/0003-066X.56.3.216

Sheridan, S. M., \& Burt, J. D. (2009). Family-Centered Positive Psychology. In C. R. Snyder, \& S. J. Lopez (Eds.), Oxford Handbook of Positive Psychology (pp. 551-559). Oxford: Oxford University Press. http://dx.doi.org/10.1093/oxfordhb/9780195187243.013.0052

Szabó, M. (2010). The Short Version of the Depression Anxiety Stress Scales (DASS-21): Factor Structure in a Young Adolescent Sample. Journal of Adolescence, 33, 1-8. http://dx.doi.org/10.1016/j.adolescence.2009.05.014

Szabó, M., \& Lovibond, P. (2006). Anxiety, Depression, and Tension/Stress in Children. Journal of Psychopathology and Behavioral Assessment, 28, 195-205. http://dx.doi.org/10.1007/s10862-005-9008-3

Tellegen, C. L., \& Sanders, M. R. (2014). A Randomized Controlled Trial Evaluating a Brief Parenting Program with Children with Autism Spectrum Disorders. Journal of Consulting and Clinical Psychology, 82, 1193-1200. http://dx.doi.org/10.1037/a0037246

Waters, L. (2011). A Review of School-Based Positive Psychology Interventions. The Australian Educational and Developmental Psychologist, 28, 75-90. http://dx.doi.org/10.1375/aedp.28.2.75

White, M., \& Waters, L. (2015). The Good School: A Case Study of the Use of Christopher Peterson's Work to Adopt a Strengths-Based Approach in the Classroom, Chapel and Sporting Fields. Journal of Positive Psychology, 10, 69-76. http://dx.doi.org/10.1080/17439760.2014.920408

Wolfradt, U., Hempel, S., \& Miles, J. N. V. (2003). Perceived Parenting Styles, Depersonalisation, Anxiety and Coping Behavior in Adolescents. Personality and Individual Differences, 34, 521-532.

http://dx.doi.org/10.1016/S0191-8869(02)00092-2 